\title{
Long-term Potentiation and Evidence for Novel Synaptic Association in CA1 Stratum Oriens of Rat Hippocampus
}

\author{
${ }^{1}$ Roche Institute of Molecular Biology \\ Nutley, New Jersey 07110 \\ ${ }^{2}$ Department of Neurological Surgery \\ University of Virginia Health Sciences Center \\ Charlottesville, Virginia 22908
}

Satoru Otani, ${ }^{1,3}$ John A. Connor, ${ }^{1}$ and William B. Levy ${ }^{2}$

\section{Abstract}

In CA1 stratum oriens of hippocampal slices, a robust long-term potentiation (LTP) induced by tetanic stimulation ( 20 pulses at $100 \mathrm{~Hz}, 10$ trains delivered at $0.1 \mathrm{~Hz}$ ) was accompanied by a slowly developing potentiation in a second, untetanized pathway. $\boldsymbol{N}$-methyl-D-aspartate (NMDA) receptor antagonist $\mathrm{DL}-2$-amino-5phosphonovaleric acid (D-APV, 50 or 100 $\mu M)$ reduced the homosynaptic LTP by $80 \%$ but failed to affect heterosynaptic LTP. The metabotropic receptor antagonist DL-2-amino-3-phosphonopropionic acid DL-AP3, $\left.300 \mu_{M}\right)$ or $(+)$ - $\alpha$-methyl-4carboxyphenylglycine (MCPG, $500 \mu \mathrm{M}$ ), applied with DL-APV, further reduced homosynaptic LTP and blocked heterosynaptic LTP. The inhibitor of $\mathrm{Ca}^{2+}$-induced $\mathrm{Ca}^{2+}$ release dantrolene (20 $\mu M)$, also applied with DL-APV, blocked both components of LTP. Importantly, when low-frequency test stimulation $(0.017 \mathrm{~Hz})$ to the untetanized, heterosynaptic pathway was interrupted for $30 \mathrm{~min}$ after homosynaptic tetanization, heterosynaptic LTP did not develop. These results demonstrate homosynaptic and heterosynaptic LTP inductions in stratum oriens of the area CA1 and suggest that the heterosynaptic LTP is induced by NMDA-independent, novel associative processes between tetanized and untetanized pathways.

${ }^{3}$ Corresponding author.

\section{Introduction}

Input specificity and associativity are two important characteristics of long-term potentiation (LTP) as a memory model. LTP is induced specifically in synapses that are stimulated repetitively (Andersen et al. 1977; Lynch et al. 1977; Levy and Steward 1979) and that are coactive with a sufficient postsynaptic activation (Levy and Steward 1979; Gustafsson and Wigström 1986; Kelso and Brown 1986; Larson and Lynch 1986; Sastry et al. 1986). These characteristics are believed to derive from $\mathrm{Ca}^{2+}$ entry through synaptically activated voltage-dependent, $\boldsymbol{N}$-methyl-D-aspartate (NMDA) receptor/channels (Bliss and Collingridge 1993). However, it is known that in CA1 neurons, LTPinducing tetanic stimulus also causes NMDA receptor-independent extrasynaptic increases of intracellular $\mathrm{Ca}^{2+}$ concentration $\left(\left[\mathrm{Ca}^{2+}\right]_{\mathrm{i}}\right)$ ( Regehr et al. 1989; Regehr and Tank 1990). This widespread rise in $\left[\mathrm{Ca}^{2+}\right]_{i}$ raises the possibility that LTP induction might spread beyond the activated synapses so as to lose spatial specificity. Nevertheless, previous studies conducted in the stratum radiatum (Dunwiddie and Lynch 1978) and between stratum radiatum and stratum oriens (Andersen et al. 1977; Lynch et al. 1977) showed that LTP in CA1 is restricted to activated synapses. In this study we conducted a series of experiments to examine and characterize homosynaptic and heterosynaptic components of LTP in stratum oriens.

\section{Materials and Methods}

Male adult Sprague-Dawley rats (160-220 grams) were anesthetized with sodium pentobar-

LEARNING \& MEMORY 2:101-106 @ 1995 by Cold Spring Harbor Laboratory Press ISSN1072-0502/95 \$5.00

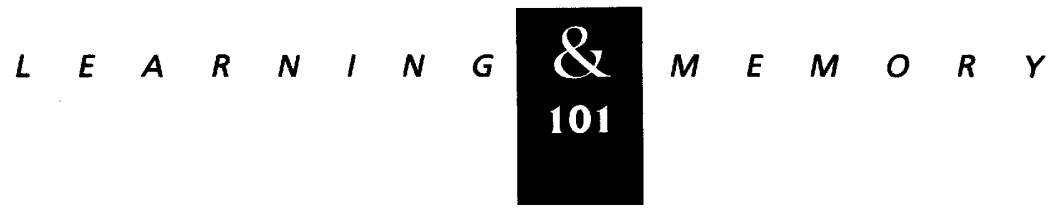


bital ( $40 \mathrm{mg} / \mathrm{kg}$, i.p.) or with a combination of ketamine $(40 \mathrm{mg} / \mathrm{kg}$, i.m.) and xylazine $(5 \mathrm{mg} / \mathrm{kg}$, i.m.) and decapitated. The brain was removed, and the right hippocampus was dissected out. Using a Vibratome or a Stoelting tissue chopper, transverse slices $(400 \mu \mathrm{m})$ were prepared from the dorsal mid-portion. Slices were kept for at least 90 min in continuously oxygenated artificial cerebrospinal fluid (CSF) of the following composition: $127 \mathrm{~mm} \mathrm{NaCl}, 2 \mathrm{~mm} \mathrm{KCl}, 2 \mathrm{~mm} \mathrm{CaCl}, 1.5 \mathrm{~mm}$

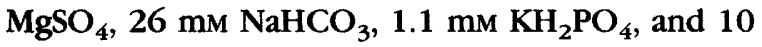
mM D-glucose. For experiments, a slice was transferred to an interface chamber, where they were continuously perfused with warmed $\left(33^{\circ} \mathrm{C}\right)$, oxygenated, artificial CSF $(1.5-2.5 \mathrm{ml} / \mathrm{min})$. CA1 region was separated from CA3 by a knife cut of Schaffer collaterals to reduce spontaneous presynaptic activity.

Extracellular responses were recorded from stratum oriens of CA1 with a glass micropipette filled with $0.9 \% \mathrm{NaCl}$ (Fig. 1). Twisted tungsten wires $(25 \mu \mathrm{m})$ were used as a bipolar stimulating electrode. One electrode was placed on each side of the recording electrode to alternatively stimulate separate sets of fibers orthodromically (S1) or antidromically (S2) $(0.017 \mathrm{~Hz}$ at one input). Stimulus consisted of constant current square pulses of

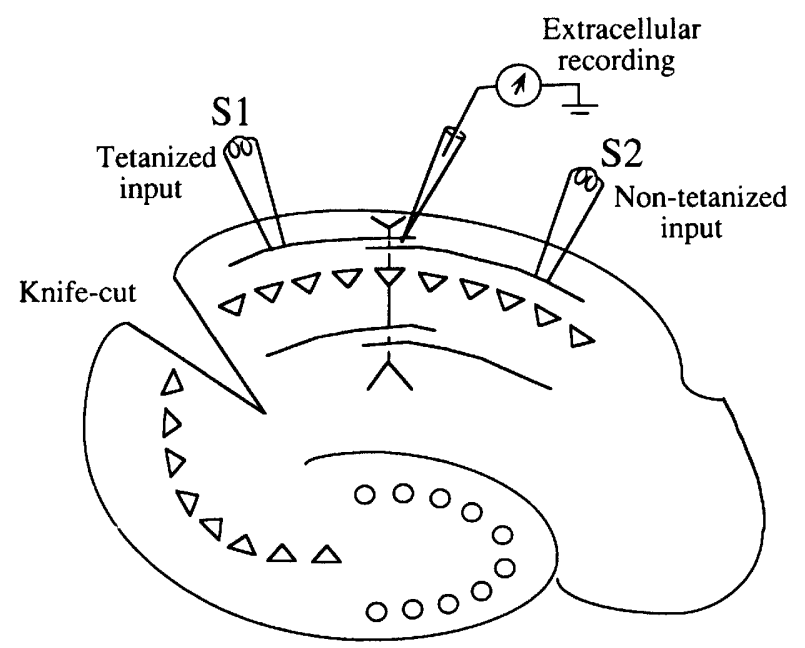

Figure 1: Schematic representation of the experimental setup in stratum oriens of a hippocampal slice. One stimulating electrode was placed on each side of the extracellular recording electrode. Two inputs were alternatively stimulated $(0.017 \mathrm{~Hz}$ at one input). In all experimental groups, the orthodromic input (S1) received LTP-inducing tetanic stimulation (20 pulses at $100 \mathrm{~Hz}, 10$ times at $0.1 \mathrm{~Hz}$ ). CA3 region was separated from CA1 by a knife cut.
$100 \mu \mathrm{sec}$ width. Intensity was set to evoke a field excitatory postsynaptic potential (EPSP) of $\sim 0.5$ $\mathrm{mV}$ amplitude (50-100 $\mu \mathrm{A})$. LTP-inducing tetanic stimulation consisted of 10 trains of 20 pulses at $100 \mathrm{~Hz}$ delivered every $10 \mathrm{sec}$. The trains were always applied to S1 pathway. During LTP induction, S2 pathway was not stimulated. Test pulses to $\mathrm{S} 1$ and $\mathrm{S} 2$ were resumed $10 \mathrm{sec}$ after the last train with the S1-S2 sequence. All responses were stored in an on-line computer. For analysis, five consecutive responses were averaged and the initial slope of the EPSP $(\mathrm{mV} / \mathrm{msec})$ was calculated. LTP was expressed as a percentage increase of the EPSP slope from a 5-min period just before tetanic stimulation. All values are expressed as mean \pm s.E.M.

The independence of two pathways was tested in six slices in the presence of bicuculline, using paired pulse test (30-msec interpulse interval). The percentage facilitation of $\$ 2$ response by S1-S2 pair was $3.8 \pm 3.6 \%$. In the same slices, facilitation of S1 response by S1-S1 pair was $151 \pm 43 \%$, indicating a minimum fiber overlap in these slices (see Results for paired pulse test in experiments without bicuculline).

Drugs used were bicuculline methochloride ( $5 \mu \mathrm{M}$, Sigma), DL-2-amino-5-phosphonovaleric acid (DL-APV, 50 or $100 \mu \mathrm{M}$, Sigma), DL-2-amino-3-phosphonopropionic acid (DL-AP3, $300 \mu \mathrm{M}$, Sigma), (+)- $\alpha$-methyl-4-carboxyphenylglycine (MCPG, $500 \mu \mathrm{M}$, Tocris Cookson), and dantrolene ( $20 \mu \mathrm{M}$, Sigma).

\section{Results}

\section{HOMO- AND HETEROSYNAPTIC LTP IN STRATUM ORIENS}

In the presence of bicuculline, tetanization of the $\mathrm{S} 1$ input induced a robust homosynaptic LTP ( $404 \pm 55 \%$ at $5 \mathrm{~min}, n=7$, Fig. $2 \mathrm{~A}$, solid squares). This LTP was accompanied by a slowly developing potentiation in the untetanized S2 input ( $26 \pm 9.8 \%$ at $30 \mathrm{~min}$, Fig. $2 \mathrm{~A}$, open squares). We tested the involvement of NMDA receptors in these homosynaptic and heterosynaptic components of LTP. Tetani were delivered in the presence of the NMDA receptor antagonist DL-APV ( 50 or $100 \mu \mathrm{M})$. There was a large $(\sim 80 \%$ at $5 \mathrm{~min})$ reduction of homosynaptic LTP (Fig. 2B, solid squares; $F(1,9)=9.56, P=0.013$, during $60 \mathrm{~min}$, $n=7$ ). In contrast, heterosynaptic LTP was un-

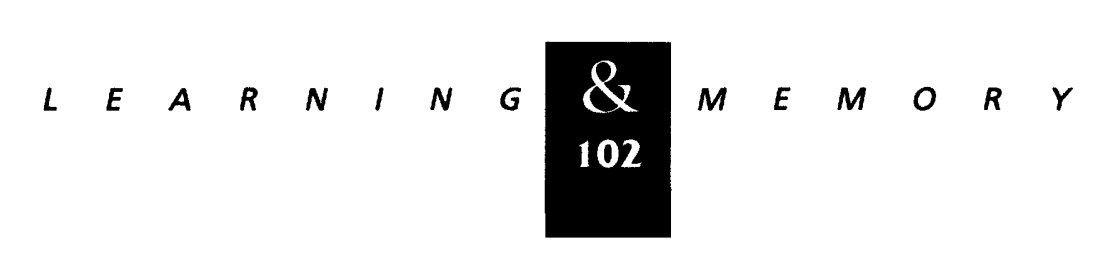




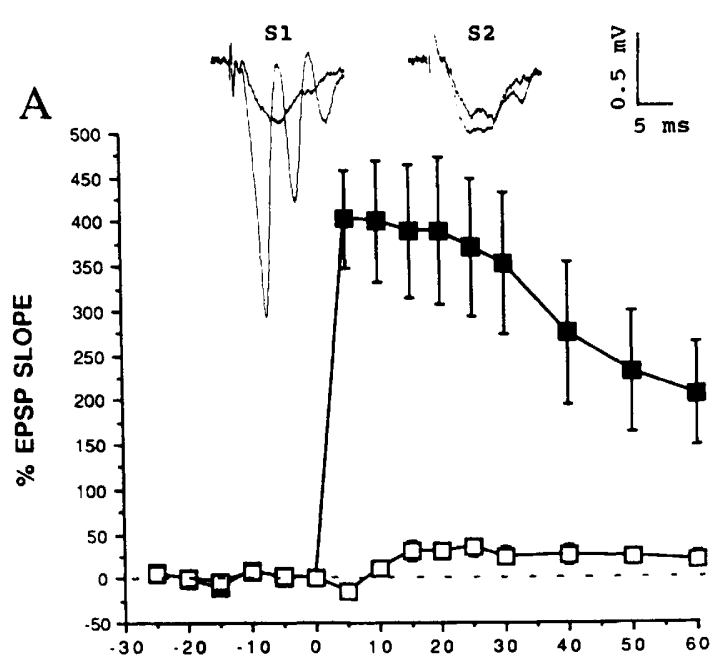

B

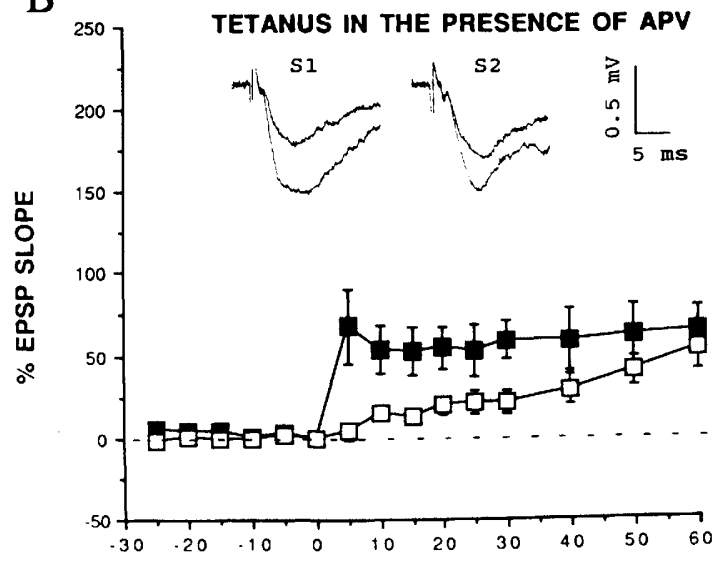

TIME RELATIVE TO LTP INDUCTION (MIN)

Figure 2: Homo- and heterosynaptic LTP in stratum oriens. (A) A robust homosynaptic LTP in S1 input was accompanied by a slowly developing heterosynaptic LTP in untetanized S2 input. (B) Effects of the NMDA receptor antagonist DL-APV (50 or $100 \mu \mathrm{M}$ ). Homosynaptic LTP was reduced but not heterosynaptic LTP. DLAPV was present in the bath from 15 min before tetanus until either 15-30 min after tetanus or the end of the experiment. Bicuculline $(5 \mu \mathrm{M})$ was present throughout the experiments. All values are mean \pm S.E.M.. Upper traces are representative averaged responses taken just before and 60 min after tetanus. ( $\square$ ) S1; ( $\square$ ) S2.

changed (Fig. 2B, open squares; $F(1,9)=0.079$, $P=0.79$ ). If anything, heterosynaptic LTP in the presence of APV showed a progressive increase compared with the control. This was confirmed by two-way analysis of variance $(F(8,72)=5.17$, $P=0.0001$ ), which indicates a significant difference in the time course of heterosynaptic LTP during $60 \mathrm{~min}$ between the two groups.
Blockade of $\gamma$-aminobutyric acid $\left(\mathrm{GABA}_{\mathrm{A}}\right)$ mediated inhibition increases the degree and probability of induction of LTP, but it is not an absolute requirement. Tetanization in the absence of bicuculline induced homosynaptic LTP in all slices $(120 \pm 32 \%$ at $5 \mathrm{~min}$ and $95 \pm 27 \%$ at $60 \mathrm{~min}$, $n=10$ ). The mean increase is smaller than where inhibition is blocked but still larger than LTP normally seen in stratum radiatum. There was a slowly developing heterosynaptic LTP in 5 of the 10 slices $(31 \pm 5.9 \%$ at $60 \mathrm{~min}$ ). Thus, heterosynaptic LTP still occurs in the absence of bicuculline, although a blockade of synaptic inhibition facilitates its induction.

In all cases, heterosynaptic LTP developed slowly in contrast to homosynaptic LTP, which had an immediate onset. This fact indicates that heterosynaptic LTP is not attributable to fiber overlap between $\mathrm{S} 1$ and $\mathrm{S} 2$ inputs. To confirm this notion, we compared paired pulse facilitation of S2 responses in S1-S2 pairs (30-msec interval) with that in S2-S2 pairs in the non-bicuculline slices (see also Materials and Methods). The mean percentage increase of the S2 response with S2-S2 pairing was $131 \pm 11 \%$. The mean S2 facilitation seen after $\mathrm{S} 1-\mathrm{S} 2$ pairing was $21 \pm 4.4 \%$. The degree of these facilitations (especially that after the S1S2 pairing) is exaggerated, as the second pulse was evoked during membrane hyperpolarization evoked by the first pulse. This hyperpolarization effect was confirmed by intracellular recording (three cells). One cell, which showed $17 \%$ S2 facilitation in S1-S2 pair, had a larger inhibitory postsynaptic potential than the other two ( $4 \%$ and $0 \%$ facilitations in these cells). Moreover, even if the paired pulse facilitation reflects the degree of fiber overlap, we found no correlation between paired pulse facilitation (in S1-S2 pairs) and the degree of heterosynaptic LTP (60 min after tetanization, $r=0.12$ ). From these observations, we conclude that fiber overlap is not the factor that determines the magnitude of heterosynaptic LTP.

\section{INVOLVEMENT OF METABOTROPIC RECEPTORS AND INTERNAL $\mathrm{Ca}^{2+}$}

We next tested the involvement of metabotropic glutamate receptors (mGluRs) and internal $\mathrm{Ca}^{2+}$ in homosynaptic and heterosynaptic LTP. First, DL-AP3 $(300 \mu \mathrm{M})$, a weak antagonist of mGluR-linked phosphoinositide hydrolysis (Schoepp and Conn 1993), was bath-applied in

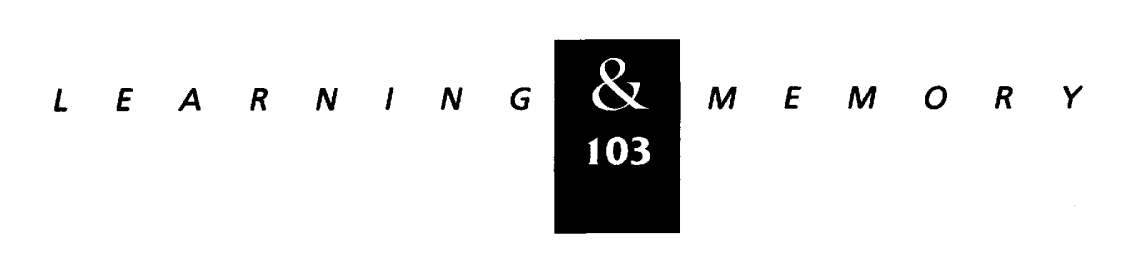


combination with DL-APV. This treatment reduced homosynaptic LTP over that with APV alone (Fig. $3 \mathrm{~A}$, solid squares; $F(1,10)=6.78, P=0.026, n=7)$ and abolished heterosynaptic LTP (Fig. 3A, open squares; $F(1,10)=8.62, P=0.015)$. The second mGluRs antagonist, MCPG $(500 \mu \mathrm{M})$, was also bath-applied in combination with APV $(n=4)$. Under this condition, homosynaptic potentiation decayed within $30 \mathrm{~min}$ after tetanization ( $24 \pm 7 \%$ at $10 \mathrm{~min}$ and $-0.6 \pm 11.5 \%$ at $30 \mathrm{~min}$ ). There was no heterosynaptic LTP; the S2 input showed a small depression $(-10 \pm 6.4 \%$ at $30 \mathrm{~min}$ and $-22 \pm 16 \%$ at $60 \mathrm{~min})$.
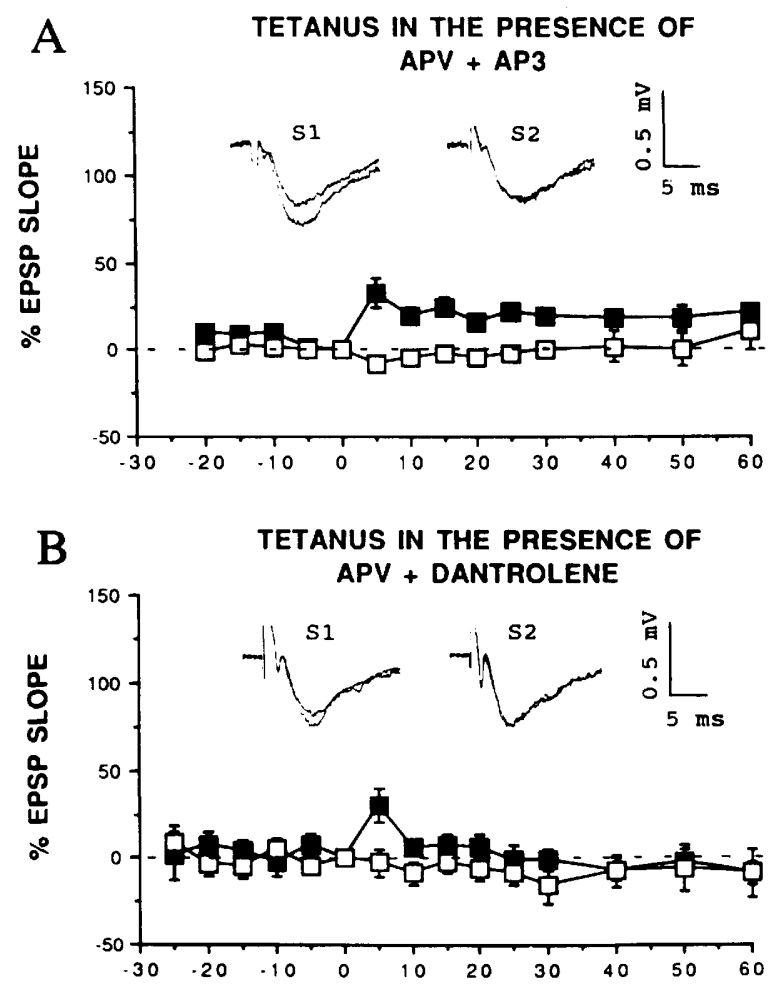

TIME RELATIVE TO LTP INDUCTION (MIN)

Figure 3: Involvement of AP3-sensitive mGluRs and $\mathrm{Ca}^{2+}$-induced $\mathrm{Ca}^{2+}$ release in homo- and heterosynaptic LTP. (A) DL-AP3 (300 $\mu \mathrm{M})$, applied with APV, further reduced homosynaptic LTP. Under this condition, heterosynaptic LTP was absent. (B) Dantrolene (20 $\mu \mathrm{M})$, applied with APV, blocked both homo- and heterosynaptic LTP. Drugs were present in the bath from $15 \mathrm{~min}$ before tetanus until either 15-30 min after tetanus or the end of experiment. Bicuculline $(5 \mu \mathrm{M})$ was present throughout the experiments. Although the size of the afferent fiber volley appears different between the baseline trace and the post-tetanization trace for the S1 input in the AP3 experiment, we noted that this was not a consistent finding. ( $\square$ ) S1; ( $\square$ ) S2.

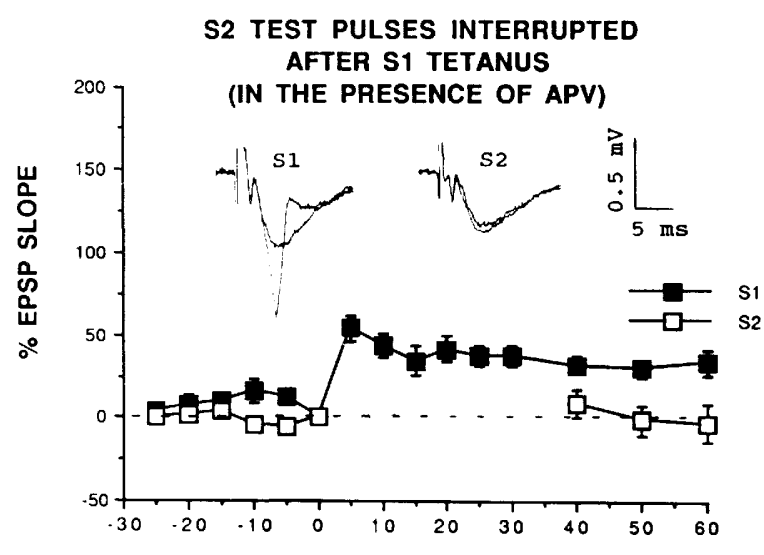

TIME RELATIVE TO LTP INDUCTION (MIN)

Figure 4: Development of heterosynaptic LTP requires single test pulses to the untetanized pathway. Test pulses $(0.017 \mathrm{~Hz})$ to $\mathrm{S} 2$ was interrupted for $30 \mathrm{~min}$ immediately after homosynaptic tetanization. No heterosynaptic LTP was seen when test stimulation was resumed. Bicuculline was present throughout the experiments. In five of seven slices used, we tested whether the stimulus interruption itself affects the responses. Prior to the experiment, the same procedure was applied without the S1 tetanus. There was no change in the field EPSP slope after a $30-\mathrm{min}$ stimulus interruption $[F(1,8)=0.68$, $P=0.433$ ].

Second, dantrolene $(20 \mu \mathrm{M})$, the inhibitor of $\mathrm{Ca}^{2+}$-induced $\mathrm{Ca}^{2+}$ release from caffeine-sensitive stores (Thayler et al. 1988; Frandsen and Schousboe 1991), was applied with DL-APV $(n=5)$. This agent blocked both components of LTP (homosynaptic input, $F(1,9)=10.38, P=0.011$; heterosynaptic input, $F(1,9)=9.52, P=0.013$; Fig. 3B).

\section{DEPENDENCE OF HETEROSYNAPTIC LTP ON POST-TETANIZATION SYNAPTIC ACTIVITY}

The slow growth of heterosynaptic LTP suggests that its development may require ongoing synaptic activity. To test this possibility, $0.017 \mathrm{~Hz}$ test stimulation to the heterosynaptic pathway was interrupted for $30 \mathrm{~min}$ beginning immediately after homosynaptic tetanization. The experiments were conducted in the presence of DL-APV, because there was a larger heterosynaptic LTP under this condition (Fig. 2B). As shown in Figure 4, no heterosynaptic LTP was detected when S2 stimulation was resumed $(-2.9 \pm 12 \%$ at $60 \mathrm{~min}$, $F(1,11)=8.47, P=0.014, n=7)$ despite the presence of homosynaptic LTP $(34 \pm 8.1 \%$ at $60 \mathrm{~min})$.

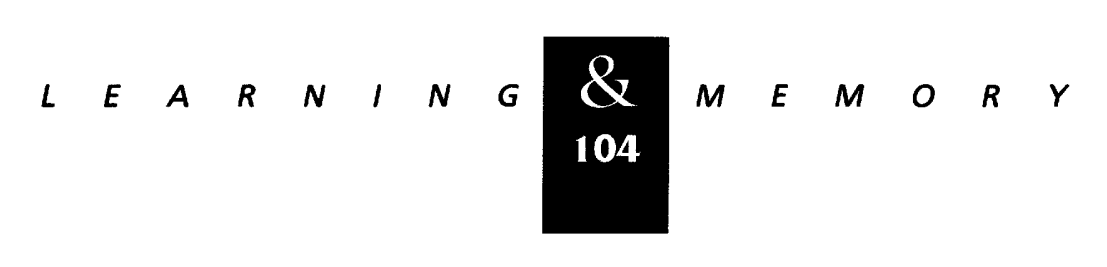




\section{Discussion}

We have shown that LTP in stratum oriens consists of homosynaptic and heterosynaptic components. Homosynaptic LTP induction depends largely on NMDA receptor activation. Heterosynaptic LTP is independent of the NMDA receptor but dependent on the activation of mGluRs and dantrolene-sensitive mechanisms. More important, the induction of heterosynaptic LTP requires continued synaptic input to this pathway following homosynaptic tetanization. We excluded the possibility that the heterosynaptic LTP reflects a potentiation that occurred in fibers shared by two pathways. There was no correlation between the degree of paired pulse facilitation in S1-S2 pairs and the degree of heterosynaptic LTP. It thus appears safe to conclude that the induction of heterosynaptic LTP is attributable to some active interaction between tetanized and untetanized pathways.

Conventional synaptic association in LTP is believed to derive from a postsynaptic depolarization acting on NMDA receptors/channels (Levy and Steward 1979; Gustaffson and Wigström 1986; Kelso and Brown 1986; Larson and Lynch 1986; Sastry et al. 1986). Duration of the depolarization may determine the very narrow time window ( $<100$ msec; Levy and Steward 1983; Gustafsson and Wigström 1986) between homosynaptic tetanus and the associative heterosynaptic input. In contrast, the synaptic association reported in this study does not require NMDA receptors and develops extremely slowly. The time window is at least $40 \mathrm{sec}$, the interval between the last tetanus and the first heterosynaptic stimulation. It is unlikely that such a slow association is caused by depolarization. Rather, it might involve biochemical processes such as phosphoinositide hydrolysis triggered by mGluRs stimulation.

A similar phenomenon has been reported by Bradler and Barrionuevo $(1989,1990)$ in the area CA3 of hippocampal slices. In their studies, mossy fiber tetanization was accompanied by a slowly developing, NMDA-independent potentiation of non-mossy fiber inputs. There are lines of evidence also in stratum radiatum of CA1 that NMDAindependent LTP develops slowly. First, Grover and Teyler (1990) showed that NMDA-independent homosynaptic LTP induced by tetanic stimulation develops gradually to test pulses. Second, LTP induced by intracellular $\mathrm{Ca}^{2+}$ release from a photosensitive caged compound develops slowly to test stimulations (Malenka et al. 1988). Third, bath application of the $\mathrm{K}^{+}$channel blocker tetraethylammonium (TEA) induces slowly developing NMDA-independent LTP (Aniksztejn and Ben-Ari 1991; Petrozzino and Connor 1994). Induction of this LTP requires mGluR activation and synaptic input (Petrozzino and Connor 1994). Fourth, repeated postsynaptic depolarizing pulses produce LTP in the presence of APV if the pulses are applied during 2-Hz synaptic stimulations (Kullmann et al. 1992). Fifth, pharmacological activation of mGluRs can induce NMDA-independent, gradually developing potentiation in stratum radiatum (Bortolloto and Collingridge 1993). Thus, internal $\left[\mathrm{Ca}^{2+}\right]$ increases via non-NMDA sources may give rise to a synaptic potentiation that develops more slowly than NMDA-dependent LTP, requiring ongoing synaptic activity.

However, the slow association between tetanized and untetanized pathways, as shown in stratum oriens in the present study, does not occur in stratum radiatum (Dunwiddie and Lynch 1978; S. Otani, unpubl.), between stratum radiatum and stratum oriens (Andersen et al. 1977; Lynch et al. 1977; Abraham and Wickens 1991), and in dentate gyrus (Levy and Steward 1979, 1983; Abraham and Goddard 1983). Lack of temporally close heterosynaptic activity may rather result in heterosynaptic depression in these areas. In stratum oriens, where homosynaptic LTP is larger than stratum radiatum (cf. Kaibara and Leung 1993) and the dendritic $\mathrm{Ca}^{2+}$ accumulation during depolarization appears also larger than in radiatum (Regehr et al. 1989), the NMDA-independent processes may form association with low-frequency inputs to adjacent synapses on the same dendritic tree.

In conclusion, this study provides the evidence for a slowly occurring synaptic interaction in CA1 stratum oriens. This novel type of association may have important implications for learning and memory in the brain.

\section{Acknowledgments}

We thank Dr. N.L Desmond for comments on the manuscripts and Mr. R. Sun and Ms. L.M. Verselis for technical assistance. The work conducted in University of Virginia was supported by grants NS15488 and KO2 from the National Institutes of Health MH00622 to W.B.L.

\section{References}

Abraham, W.C. and G.V. Goddard. 1983. Asymmetric relationships between homosynaptic long-term potentiation

$$
\begin{array}{llllllll}
L & E & A & R & N & I & N & G \\
\begin{array}{l}
\boldsymbol{Q} \\
105
\end{array} & M & E & M & O & R & Y
\end{array}
$$


Otani et al.

and heterosynaptic long-term depression. Nature 305: 717-719.

Abraham, W.C. and J.R. Wickens. 1991. Heterosynaptic long-term depression is facilitated by blockade of inhibition in area CA1 of the hippocampus. Brain Res. 546: 336-340.

Andersen, P., S. Sundberg, H. Sveen, and H. Wigström. 1977. Specific long-lasting potentiation of synaptic transmission in hippocampal slices. Nature 266: 736-737.

Aniksztejn, L. and Y. Ben-Ari. 1991. Novel form of long-term potentiation produced by a $\mathrm{K}^{+}$channel blocker in the hippocampus. Nature 349: 67-69.

Bliss, T.V.P. and G.L. Collingridge. 1993. A synaptic model of memory: Long-term potentiation in the hippocampus. Nature 361: 31-39.

Bortolotto, Z.A. and G.L. Collingridge. 1993. Characterization of LTP induced by the activation of glutamate metabotropic receptors in area CA1 of the hippocampus. Neuropharmacology 32: 1-9.

Bradler, J.E. and G. Barrionuevo. 1989. Long-term potentiation in hippocampal CA3 neurons: tetanized input regulates heterosynaptic efficacy. Synapse 4: 132-142.

1990. Heterosynaptic correlates of long-term potentiation induction in hippocampal CA3 neurons. Neuroscience 35: 265-271.

Dunwiddie, T. and G. Lynch. 1978. Long-term potentiation and depression of synaptic responses in the rat hippocampus: localization and frequency dependency. J. Physiol. 276: 353-367.

Frandsen, A. and A. Schousboe. 1991. Dantrolene prevents glutamate cytotoxicity and $\mathrm{Ca}^{2+}$ release from intracellular stores in cultured cerebral cortical neurons. J. Neurochem. 56: $1075-1078$.

Grover, L.M. and T.J. Teyler. 1990. Two components of long-term potentiation induced by different patterns of afferent activation. Nature 347: 477-479.

Gustafsson, B. and H. Wigström. 1986. Hippocampal long-lasting potentiation produced by paring single volleys and brief conditioning tetani evoked in separate afferents. /. Neurosci. 6: 1575-1582.

Kaibara, T. and L.S. Leung. 1993. Basal versus apical dendritic long-term potentiation of commissural afferents to hippocampal CA1: A current-source density study. I. Neurosci. 13: 2391-2404.

Kelso, S.R. and T.H. Brown. 1986. Differential conditioning of associative synaptic enhancement in hippocampal brain slices. Science 232: 85-87.

Kullmann, D.M., D.J. Perkel, T. Manabe, and R.A. Nicoll. 1992. $\mathrm{Ca}^{2+}$ entry via postsynaptic voltage-sensitive $\mathrm{Ca}^{2+}$ channels can transiently potentiate excitatory synaptic transmission in the hippocampus. Neuron 9: 1175-1183.
Larson, J. and G. Lynch. 1986. Induction of synaptic potentiation in hippocampus by patterned stimulation involves two events. Science 232: 985-988.

Levy, W.B and O. Steward. 1979. Synapses as associative memory elements in the hippocampal formation. Brain Res. 175: 233-245.

1983. Temporal contiguity requirements for long-term associative potentiation/depression in the hippocampus. Neuroscience 8: 791-797.

Lynch, G.S., T. Dunwiddie, and V. Gribkoff. 1977. Heterosynaptic depression: a postsynaptic correlate of long-term potentiation. Nature 266: 737-739.

Malenka, R.C., J.A. Kauer, R.S. Zucker, and R.A. Nicoll. 1988. Postsynaptic calcium is sufficient for potentiation of hippocampal synaptic transmission. Science 242: 81-84.

Petrozzino, J.J. and J.A. Connor. 1994. Dendritic $\mathrm{Ca}^{2+}$ accumulations and metabotropic glutamate receptor activation associated with an N-methyl-D-aspartate receptor-independent long-term potentiation in hippocampal CA1 neurons. Hippocampus 4: 546-558.

Regehr, W.G. and D.W. Tank. 1990. Postsynaptic NMDA receptor-mediated calcium accumulation in hippocampal CA1 pyramidal cell dendrites. Nature 345: 807-810.

Regehr, W.G., J.A. Connor, and D.W. Tank. 1989. Optical imaging of calcium accumulation in hippocampal pyramidal cells during synaptic activation. Nature 341: 533-536.

Sastry, B.R., J.W. Goh, and A. Auyeung. 1986. Associative induction of posttetanic and long-term potentiation in CA1 neurons of rat hippocampus. Science 232: 988-990.

Schoepp, D.D. and P.J. Conn. 1993. Metabotropic glutamate receptors in brain function and pathology. Trends Pharmacol. Sci. 14: 13-20.

Thayer, S.A., L.D. Hidning, and R.J. Miller. 1988. The role of caffeine-sensitive calcium stores in the regulation of the intracellular free calcium concentration in rat sympathetic neurons in vitro. Mol. Pharmacol. 34: 664-673.

Received March 14, 1995; accepted in revised form May 26, 1995.

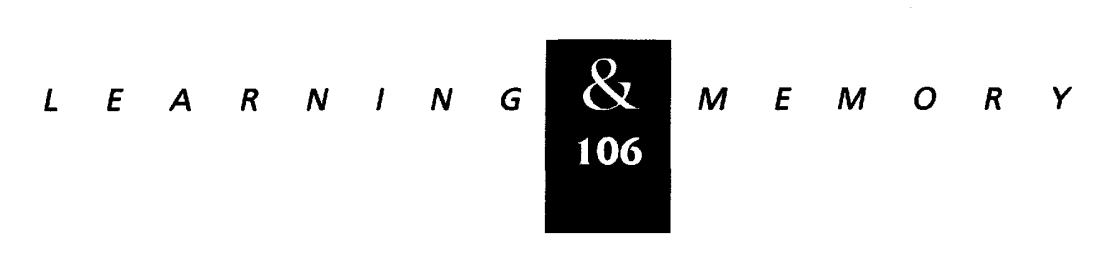




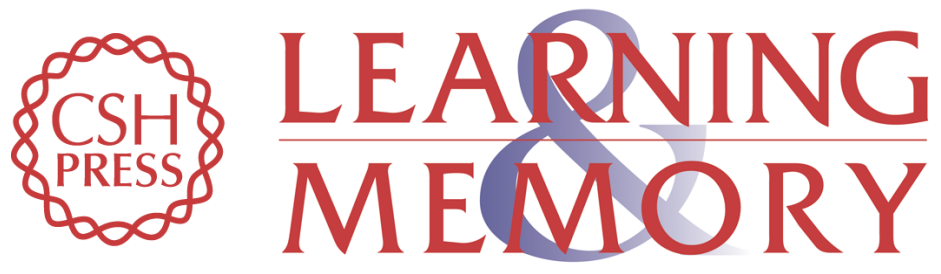

\section{Long-term potentiation and evidence for novel synaptic association in CA1 stratum oriens of rat hippocampus.}

S Otani, J A Connor and W B Levy

Learn. Mem. 1995, 2:

Access the most recent version at doi:10.1101//m.2.2.101

References This article cites 26 articles, 7 of which can be accessed free at: http://learnmem.cshlp.org/content/2/2/101.full.html\#ref-list-1

License

Email Alerting Receive free email alerts when new articles cite this article - sign up in the box at the Service top right corner of the article or click here. 